\title{
CRISIS OF ETHNIC IDENTITY WITH LANGUAGE LOSS OF ORAON TRIBE
}

\section{Ms. Stuti Bhagat}

"Why do you want to learn your language?", "Learn English! the children speak in English fluently", "What's your mother tongue? - 'Hindi", "You belong to a tribe and you don't you know your tribal language?" -- these are common remarks that the migrating people of a tribe settled in other areas, have to face. They usually avoid these questions or end up learning the language with the highest sociolinguistic capital in their surrounding context. Over a course of time, the language of their ethnic identity gets increasingly replaced in more and more domains. While these substitutions are taking place, when an individual contemplates about identity, the one thing that goes missing is the ethnic identity. Individuals not born and brought up around their tribe, lack the cultural and linguistic competence to appreciate one's own ethnic identity. In course of time, this gives rise to an identity crisis. This crisis is not limited to one level, but on a wider arena there is language loss taking place. The reasons can be social, political, cultural, etc. Social reasons feature most prominently for all the stated problems and the strange questions that are asked. So, in the paper, attempts have been made to dissect the mentioned issues in vivid detail.

Keywords: Diglossia, bilingualism, multilingualism, language loss \& di-ethnia.

\section{INTRODUCTION}

The basic aim of the paper is to investigate the notion of di-ethnicity with regard to the kurux speakers. Kurux is an endangered tribal language. The highlight is also on how the kurux speakers have become proficient bilinguals and multilinguals and in the process they prioritize one of the languages. 
Towards Excellence: An Indexed, Refereed \& Peer Reviewed Journal of Higher Education / Ms. Stuti Bhagat / Page 26-36

Questioning one's ethnic identity with respect to language, will help ascertain the presence of di-ethnia. If di-ethnia does feature, then how is an individual's ethnic identity projected. Language manipulation and change are witnessed prominently in the present generation. Through these, the objective is to check for the ethnic acceptance of these speakers. Another concern is, how much willing the speakers actually are, to do something about their language; what would they do to preserve their language which would imply preserving an essential component of their identity. As a tribe, efforts to save the language would entail preserving the worldview encrypted in the language.

\section{A BRIEF BACKGROUND OF THE KURUX TRIBAL LANGUAGE}

Kurux goes by many names like Kishan, Kunah, Kunurkh, Oraon, etc. Oraon is the name recognized by the government and is used for any kind of reference to them. This name was given (i.e. Oraon) by the outsiders (people who are not a part of the tribe). Initially, members of this tribal group were mainly involved in household activities, working as servants in the houses of outsiders. However, their primary occupation is agriculture. It is only recently that they have started venturing to other domains like government jobs, academics and others.

They are an important Dravidian tribe of the Chottanagpur plateau. In course of time, they have moved out and settled in various states of India viz. Bihar, Jharkhand, West Bengal, Assam, Orissa, and others. The members of the tribe prefer being referred to as kurux, although the authorities identify them as Oraon. Some consider the term 'Oraon' to be somewhat derogatory as it carries a racial reminder of their complexion. The language spoken by the kurux speakers is kurux. They are multilingual as they have come into contact with several languages in course of their migration to different parts of India. The below flowchart is an outline of the language family to which Kurux belongs: 


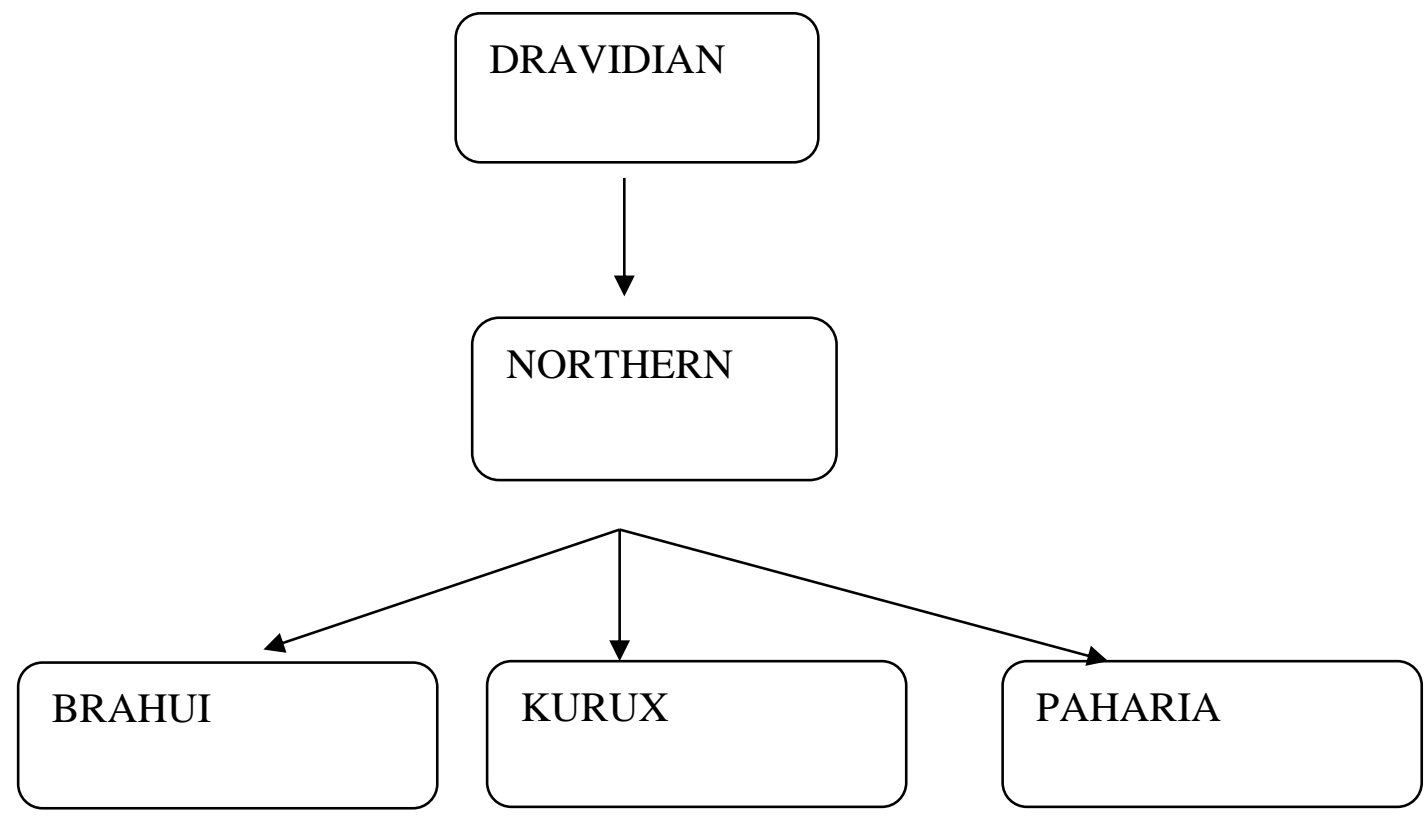

The kurux tribe has both Christians and non-Christians. The bulk of the tribal population converted to Christianity. Some remained as non-Christians and practiced religious rituals in the way their ancestors did, i.e. by worshipping nature. For this tribe, worshipping nature continues to be significant, as from the primitive times, it is nature that supported their lives and existence. Initially, none of the followers did ever change their language from kurux to anything else. Even when the missionaries started preaching, they did encourage people to convert but never tried to take away their indigenous language. Instead, to facilitate understanding, they translated the Christian concepts into the tribal language. Significantly, the non-Christians still use kurux as the language of religious rituals and songs. They are efficient multi-linguals knowing multiple languages like Hindi, English, and other languages of the states where they have resided for long (India is a highly-diversified country in terms of language).

People have been shifting or migrating to different corners of India for quite some time, for different reasons like education, occupation. So much movement compelled them to learn different languages to coalesces with the local populations. In course of time, this 
Towards Excellence: An Indexed, Refereed \& Peer Reviewed Journal of Higher Education / Ms. Stuti Bhagat / Page 26-36

pushed kurux to undergo a gradual process of change, both morphologically and phonologically.

The main motive is to look into the idea of ethnicity. The people of this tribe describe their ethnic identity as Oraon/Kurux. The aim is to show di-ethnia existing within the tribe through language, along with how language loss is taking place. This leads to the entire formal identity of ethnicity getting deconstructed on a formal basis.

\section{BiLinguALISM, MulTiLingualiSM \& Diglossia}

The people of this tribe are not monolinguals; they have learnt the languages of the states where they have migrated and have learnt languages like Bengali, Hindi, etc. It's not that only the Oraon tribe settled in this particular geographical region. There are other tribes in this area like Kharia, Munda, Ho, etc. Some have learnt the other tribal languages while some make use of Sadhri or Nagpuri to communicate. It also serves as the lingua franca (common language for communication) for all the tribes residing around. Multilingualism is remarkably conspicuous in the tribe. This shifts our focus to another sociolinguistic phenomenon that is diglossia.

Diglossia is that particular linguistic situation, in which a speaker makes use of two, or more languages in different domains. In this situation, there will be one language that would be considered to be the dominant one. Speakers of Kurux are highly diglossic and there are many entailed reasons. They use different language in different domains to realize different aspirations.

\begin{tabular}{|l|l|l|l|l|}
\hline Domain & Bengali & Hindi & Kurux & Multiple \\
\hline Education \& & & 14 & & \\
occupation & & & & \\
\hline
\end{tabular}


Towards Excellence: An Indexed, Refereed \& Peer Reviewed Journal of Higher Education / Ms. Stuti Bhagat / Page 26-36

\begin{tabular}{|l|l|l|l|l|}
\hline Family & & 15 & 5 & 5 (both hindi and kurux) \\
\hline Tribal friends & - & 12 & 6 & 6 (both hindi and kurux) \\
\hline Neighbours & 5 & 11 & & \\
\hline Religious rituals & - & 11 & 3 & 3 (both hindi and kurux) \\
\hline
\end{tabular}

The above table comes from a survey in which I had asked questions to 15 Kurux speakers. These participants were specifically those who had migrated to other areas (Delhi and West Bengal in particular) from their ancestral land. We can postulate that people of the tribe are, of course, practising Diglossia, but there is a priority with respect to language use. People of the tribe use Hindi in mostly all domains. In certain domains, they use both Hindi and Kurux. Their kids have no idea about their tribal language but they know the name and are aware of it.

The younger generation is highly influenced by surrounding domains that they learn Hindi, English, Bengali (depending on the states they reside). They have never made an effort to learn their language. When asked about why they have not learnt it, the young ones would just avoid the question. They would say that mastering to speak in English is more important. This goes in tandem with English being attributed the highest prestige. Evidently, prioritizing a language to this extent at the grassroots level does separate the younger generation from their roots.

On a similar line of thought, this can raise the question that how is, the younger generations' ethnic identity of being an Oraon, dealt with. The older generation, who had this language as the mother tongue, have no problem with their ethnic identity. These elders, however, don't put any effort to make their indigenous ethnic identity a concrete one for their children. This creates a confusion for the children in recognizing and describing their identity. At one point, they do experience the identity crisis problem. But, once the kids learn 
to handle things related to ethnicity, they have moved away from their origin. For them ethnicity, language, values and concerns of tribe don't matter much. I am a part of the tribal group, but not knowing our language always created a gap between me and the tribe; a gap of not being able to appreciate my values and of not knowing my language. Therefore, knowing one's language is necessary to experience oneness with the tribe and to even be a part of it.

Children often designate themselves to be a part of the tribe. However, this is usually a namesake, at least for the people who are born in places, where their tribe is a minority. Though, they make use of the government opportunities given to the tribe, this is just for the sake of making proper use of it. Though they attend their tribal festivals, that are celebrated with great enthusiasm, half of the time the children born and brought up outside are not aware of them. It's not that they can't be made aware about their rituals and festivals, it's just that they do not bother much. Mostly, they want their children to achieve some financially secure position in life. But, they forget that there would be no connection to their ethnic identity.

The older generation know the tribal language; for many it's their mother tongue/first language. In the table, the domain of phatic communication with tribal friends accounts for 6 out of 15 speakers. All these speakers are mostly from the older generation. The young ones choose to speak the dominant and other popular languages like Hindi and English in almost all domains.

When there already is an ethnic identity crisis, is there the possibility of di-ethnicity for the younger generation? Before looking into various other dimensions of the tribe, to understand whether di-ethnicity is present, it is imperative to understand what di-ethnia is.

Di-ethnia is a social situation in which two ethnicities are used or expressed in a mutually exclusive context. In this, to be a part of two ethnicities, a kind of acceptance from both the ethnic groups is needed. 
The kurux tribe, as mentioned earlier, got converted in large numbers to

Christianity. Even after that, both the non-Christians as well the Christians stayed together with proper mutual understanding. Despite becoming Christians, they celebrate tribal festivals like 'Karma'. Such a situation can be an apt example to appreciate di-ethnia within the tribe. But for the younger generation, it stands out to be differently. The non-Christians are not much aware about the tribal festivals. They only know about the Christian festivals. As they have migrated to different places and their mingling with outsiders has been conspicuous, they embrace foreign rituals and religions liberally. However, if they get a chance, they do make an effort to construct their identity of belonging to the tribe.

Cross-religion or cross-tribe marriage is accepted through mutual understanding of the families and is a very good instance to appreciate di-ethnia. In these cases, the couples have a di-ethnic identity. If the next generation, that is their children, can be taught both the languages and are made culturally aware of both the tribes, then these children will undoubtedly have di-ethnicity. Therefore, adding to the previous comment of them being diglossic, they can also be di-ethnic. One thing to remember, is that acceptance of all kinds is required i.e. acceptance from both the tribes, religious, ritual and cultural acceptance. Another important aspect is how well an individual is able to cultivate his or her di-ethnicity.

Considering all the positive aspects of the kurux tribe being di-ethnic, one thing to remember is, for the present generation there is no point talking about ethnicity, on the basis of language. This particular tribe was never that powerful economically or politically to procure a recognized space for the tribe and preserve the language. Kurux is one of the endangered languages which needs to be protected. Several steps need to be taken on a larger scale but efforts must also be there at the individual level. Kurux should be promoted at the primary level of education; at least, in places where there are majority of speakers from the kurux tribe. Children should be taught by their parents. Unfortunately, this argument cannot 
be taken into consideration as the generation that got married and whose first language wasn't kurux, would find it impossible. For such situations, which comprise the bulk, the parents don't have the zeal of knowing the language and to pass it on to their children. Hence, the number keeps increasing. This cannot be moderated, at least for the people who have migrated to other states. No matter how much they keep going to their ancestral place, the revival of the language in the present generation, is a complicated issue. When asked regarding how about giving a chance to learn the language by publishing books, having shows and movies in their language, the younger generation had answers like "Why not let it be Hindi, why such a step should be taken?". No matter how much they are aware about the language loss happening, no such step to preserver the cultural capital is taken. They know that their language is going to be extinct in the next hundred years. They are sad about it, but in the end, they don't do much about it. On the other hand, they make it a point to strongly abide by their ethnic identity of belonging to the kurux tribe. Maybe they have forgotten or they are not aware of the fact that language preservation is necessary for the tribe's survival, which would eventually follow if they learn and use the language. Language is a mode to connect with people. If there is no language, then how will a connection be established? It would eventually cause these people to move away from their tribal association. One's language is one's biggest identity. Without language, one's ethnic identity, even after belonging to a tribe, will be bleak.

\section{CONCLUSION}

Members of the Kurux tribe are, of course, aware about all the drawbacks of not knowing their language. They know that their language is one of the most endangered languages. They are, slowly but surely, taking steps to do something about it. But it is unclear, as to how much effective these measures are going to be. Conferences and talks are making the tribal people aware about these issues and many initiatives are being planned. It's 
Towards Excellence: An Indexed, Refereed \& Peer Reviewed Journal of Higher Education / Ms. Stuti Bhagat / Page 26-36

not that there is absolutely no text in kurux language. However, it doesn't seem to be of too much help as people rarely study or look for those.

The situation is worse for those who have migrated, as the children are unaware about their tribe. They are adopting and accepting values, rituals as well as languages of the outsiders. People have also started marrying non-tribal people; in the process, indigenous value systems and cultural aspects are getting lost. It doesn't matter what is happening to their language and they don't think much about it. People have moved out from their own land and migrated to different areas. They are situationally compelled to adapt to various rituals and customs that surround them. Therefore, in course of time, they modify their own rituals. But it is debatable whether it's a modification or is it about moving away from one's own roots, to be incorporated and accepted in the foreign society. Of course, there is diethnicity present within the tribe, as, by religion, they are Christians but still they celebrate the non-Christian festivals. They also follow other customs. The critical question is, for how long is this going to sustain. Alongside language, their ethnic identity is endangered.

There is something positive happening as well. Di-ethnia is constructed, even in the absence of language, based on other aspects. But language loss and an increase of diglossia, leads to the dominant language coming to power, threatening the existence of the tribal language. People do think about strengthening the tribe and saving the language, but in actuality, very little is done to implement a change.

\section{Works Cited:}

Ahmad, Sayed, et al. The Kurux of Bangladesh: A Sociolinguistic Survey.

Dhaka: SIL International, 2011. Print. 
Towards Excellence: An Indexed, Refereed \& Peer Reviewed Journal of Higher Education / Ms. Stuti Bhagat / Page 26-36

Patterson, Orlando. "Language, ethnicity, and change."

Journal of Basic Writing 3.1 (1980): 62-73. Print.

\section{Appendix :}

Questions asked to the participants :-

1.What is your mother tongue?

2.Where does your tribe originate from? (name of the place)

3. Which place are you residing at the present (name of the state) and for how long (approx) ?

4. Do you know your tribal language? If yes then how proficient are you in the language ?(in terms of understanding and communication)

5.Which language do you prefer most in the mentioned domains :-

\begin{tabular}{|l|l|}
\hline DOMAINS & LANGUAGES \\
\hline School & \\
\hline College & \\
\hline Office (if you are working) & \\
\hline Friends: & \\
\hline Family friends) & \\
\hline Spouse (if you are married) & \\
\hline Siblings & \\
\hline Neighbours & \\
\hline
\end{tabular}


Towards Excellence: An Indexed, Refereed \& Peer Reviewed Journal of Higher Education / Ms. Stuti Bhagat / Page 26-36

Religious places and rituals

6. In which language would you prefer a book/ magazine/ newspaper/ tv show to be ? Would you like it to be in your tribal language?

7. What if $\mathrm{u}$ come to know that your language is one of the endangered languages, how would you react to it?

Ms. Stuti Bhagat 